\title{
Training of future primary school teachers for the formation of functional lit- eracy in pupils
}

\author{
Valentyna Shpak ${ }^{1, *}$, Anna Klim-Klimashevska ${ }^{2, * *}$, and Tatyana Ninova $^{2, * * *}$ \\ ${ }^{1}$ The Bohdan Khmelnytsky National University of Cherkasy, 81 Shevchenko Blvd., Cherkasy, Ukraine 18031 \\ ${ }^{2}$ Department of Teacher Education, Siedlce University of Natural Sciences and Humanities, 2 Konarskiego Str., 08-110 Siedlce, Poland
}

\begin{abstract}
The main problem area of the article is the current issues of pedagogical science concerning training of future primary school teachers for the formation of functional literacy in pupils. The emergence of these issues is determined by globalization and integration processes in the educational system of Ukraine and in the world, social transformations that affect the content of primary education, as well as modern humanitarian, scientific and technological development. This requires each individual to show functional literacy. Based on this, there is an urgent need for fundamental changes in postclassical education, caused by modern European theories, educational models, the latest tools of professional activity of primary school teachers who are responsible for the provided educational services. These changes are necessary in the context of the recommendations provided by leading European and international educational organizations, and are confirmed by the results of international PISA research. The purpose of the research involves establishing the essence of the basic concept of "functional literacy" and its structure. The research found a link between functional literacy and soft skills. The program of the experiment provides for the diagnosis of the formation of functional literacy in future primary school teachers. Questionnaire and testing of final year students' in specialty 013 Primary Education of Bohdan Khmelnytsky National University of Cherkasy (Ukraine) confirmed the assumption that in most students functional literacy is formed at the middle level.
\end{abstract}

\section{Introduction}

The topicality of the research is due to the changing priorities that accompany the current reform processes in the field of primary education in Europe and Ukraine [1]. These changes mostly concern the theory and practice of teaching, critical revision of the educational paradigm, rethinking the methodology of education in the context of world trends. In this regard, current and future issues of pedagogical science need to be urgently addressed, in particular, psychological and pedagogical, philosophical and socio-cultural aspects of education, training and education of the younger generation, modern theories and technologies of primary education. The emergence of these issues is determined by globalization and integration processes, social transformations, modern humanitarian, scientific and technological development. Thus, if at the end of the 20th century parents and teachers were first interested in the educational achievements of primary school pupils, now the leading role is given to skills, related to personal qualities and attitudes, social skills and management skills. Based on this, we can conclude that the determining factor for self-realization of the individual in the educational process of primary school and subsequent stages of learning is functional literacy, rather than a fixed set of professionally oriented competencies.

\footnotetext{
*e-mail: shpakvalentina64@gmail.com

**e-mail: klimanius@interia.pl

***e-mail: ninova@ukr.net
}

Functional literacy is close to, but not identical to, soft skills. However, in the program materials of UNESCO and the European Commission, soft skills are called universal or functional competencies [2-4], and the fact of their possession is called functional literacy [5]. In the context of globalization changes in the theory and methods of teaching of future primary school teachers, there is an urgent need to establish the minimum level of functional literacy that every European needs for adequate selfrealization in society. It is no coincidence that Microsoft in the selection of applicants gives priority to public speaking and communication skills, possession of office software, and the ability to self-organization. Forbes considers communicative competence, creativity, writing quality texts, teamwork, basic computer knowledge and the ability to "re-engineer" - the willingness to do the usual things in a new way to be the most important. The German wave celebrates communication and management talents: public speaking, the ability to persuade, lead, manage, make presentations, approach people and resolve conflict situations. The British e-learning platform SkillsYouNeed highlights personal skills (time management, self-development, management of emotions and even nutrition, body care, sports training, effective sleep) and interpersonal (communication, teamwork, negotiation, conflict management), leadership skills, as well as writing skills and basic mathematical knowledge. In European countries, the content of each group of abilities is not fixed, it is constantly expanding. 
The European Dictionary of Skills and Competences contains thousands of titles and continues to grow. Based on this, we can conclude that the determining factor for selfrealization of each individual is functional literacy, rather than a fixed set of professional competencies.

UNESCO experts determine that literacy in its modern sense is more than just the ability to read and write. It means the presence of communication skills in society. Literacy refers to the social practice of the individual, social relationships, knowledge, language and culture. Literacy has many forms of expression - written, computer, media, mathematical, sign, political. The UNESCO documents [6] refer to the creation of literacy culture, which provides for the formation of a constant need to acquire and improve it throughout life, about the creation of a literate environment - a society that learns permanently throughout the period of its conscious existence.

Acquisition of functional literacy has become one of the leading civil rights, the duty of a citizen, nonfulfillment of which has negative consequences for the individual and society as a whole. In the practice of international literacy studies, which are regularly conducted by UNESCO institutes, there is such a classification of its types [6]:

- prose literacy (involves understanding different types of texts, in particular, newspaper articles, prose and poetry),

- documentary literacy (the ability to present information in a document and draw it from there),

- mathematical (computational) literacy (ability to make simple calculations and understand quantitative indicators).

This should be taken into account by future primary school teachers during the formation of functional literacy in pupils.

The International Adult Literacy Survey identifies such levels of literacy [6]:

1) the person has serious difficulties in reading, understanding and interpreting simple texts and does not realize that this is a problem,

2) the person reads simple texts, skills of their interpretation are rather limited, the problem of insufficient literacy is realized,

3) the person reads quite well, but may have difficulty understanding complex texts. Experts consider this level to be the minimum allowable for full functioning in modern society,

4) high level of literacy, which implies the presence of developed general cultural and professional skills.

The need to solve the problem of training of future primary school teachers for the formation of functional literacy in pupils is emphasized in regulations. Among them should be noted the Law of Ukraine "On Education" which emphasizes that the following skills are common to all competencies: reading comprehension, ability to express one's opinion orally and in writing, critical and systematic thinking, ability to logically substantiate position, creativity, initiative, ability to constructively manage emotions, assess risks, make decisions, solve problems, ability to cooperate with other people. In the Concept of New Ukrainian School the description of the main competencies is supplemented as ability to read and understand what is read, ability to express an opinion orally and in writing, critical thinking, ability to logically justify a position, show initiative, create, ability to solve problems, assess risks and make decisions, ability to constructively manage emotions, apply emotional intelligence, teamwork.

The skills and abilities represented in these program documents best characterize the functional literacy, on the formation of which depends the socialization of the child of primary school in society. As mentioned above, functional literacy is close in content to soft skills, as it also covers the range of personal qualities, social skills and career building skills. It is no coincidence that these soft skills are considered flexible. These skills are also called functional, and the result of their formation - functional literacy. In fact, it is the result of mastering them. It is clear that future elementary school teachers should be trained in advance for its formation in pupils. It is necessary to begin this process from the first years of study in higher school, and for this purpose during studying of disciplines of an obligatory component of professional training it is desirable to update in time the theory and a teaching technique, program results of training as close as possible to the established European requirements.

Therefore, the problem of training of future primary school teachers for the formation of functional literacy in pupils is relevant given the new trends in modern theory and methods of teaching.

The purpose of the article is to clarify the role of future primary school teachers in the formation of functional literacy of pupils. Before considering the peculiarities of training future primary school teachers for this activity, we need to define the essence of the key concept of "functional literacy", to analyze its structure. We also plan to diagnose the formation of functional literacy in future primary school teachers and pupils. In the course of the research we will try to compare functional literacy with soft skills, to find out which components of functional literacy are given priority by parents of modern schoolchildren and future primary school teachers.

\section{Literature review}

Let's try to analyze why the future destiny of each individual depends on the training of future primary school teachers for the formation of functional literacy of pupils.

Revealing the essence of the main category of the problem we study, we note that "functional literacy" is "the ability of an individual to apply all lifelong knowledge, skills and abilities to solve the widest range of life problems in various fields of activity, communication and social relations" [7]. As an argument in support of the priority role of functional literacy in the training of future 
primary school teachers, we see in the responsibility that modern society places on him. After all, it is the primary school teacher who lays the foundation for a young person, which in the long run will determine the success in the modern labor market.

In 2018 for the first time 6000 Ukrainian teenagers joined the world's largest study - PISA, which aims to forecast the state of the labor force in the labor market in the long run - in 10 years. With the help of PISA the level of mastery of three basic competencies by graduates of general secondary education institutions - reading, mathematics and natural science. "The PISA scale has six levels: 1 - least, 2- base, 3-4 - sufficient, 5-6 - the highest level. If a person has not reached the basic level in mathematical, reading and natural sciences, he will not be able to interact qualitatively with society, because he does not see the existence of science in life, cannot solve basic life problems and is not able to work with text" [8].

According to international studies, Ukraine ranks approximately 37-42 in reading, 41-46 in mathematics and 35-42 in science, which coincides with the ranking of such post-Soviet countries as Belarus, the Slovak Republic and Hungary: "In general, Ukraine lags behind countries in terms of performance indicators OECD (Organization of economic cooperation and development - founding countries PISA) 39 points in mathematics, 23 points in reading and 22 points in natural sciences" [8]. It is believed that the best results have now been achieved in those countries where the education system has been intensively reformed.

Let's dwell in more detail on the consequences that this result has in the future for the full functioning of graduates of general secondary education in society. Our analysis of normative documents and research results of scientists confirms: the leading criterion quality of their education is "reading competence" as the ability to understand printed texts, use them to achieve their own goals, development of knowledge and opportunities, active participation in public life. In our opinion, in terms of content, "reading competence" is synonymous with "functional literacy", which has a general educational significance. In our opinion, the level of functional literacy of Ukrainian pupils is characterized by academicism, theoretically oriented nature, which does not allow to effectively solving everyday problems, to navigate freely in situations of life choices, to work with an informative array of media.

Among the reasons for this situation in general secondary education, Marta Kondracka-Szala amd Joanna Malinowska [9], Safiyeh Shami and Naser Nastiezaie [10], Rissaphop Treesuwan and Tanes Tanitteerapan [11], call the lack of practical orientation and detachment from the realities of life science and mathematics training, overload of curricula and textbooks, lack of attention to the formation of primary school pupils learning and intellectual skills, and they lack a critical attitude to the perceived information, the ability to interpret it in accordance with changed conditions and circumstances. The way out of this situation is seen in strengthening the quality of education and the introduction of a person-centered model of learning at all levels, starting with the primary school.
It is clear that only a primary school teacher who is aware of this problem can form a functionally literate personality. Given the results of their own research let's try to identify the components of "functional literacy" as a key competence of a primary school pupils:

1) orientation in the environment in accordance with accepted values, expectations and interests;

2) ability to make decisions independently and take responsibility in a situation of choice;

3) ability to be responsible for decisions made, as well as to be responsible for their family members;

4) formation of the ability to learn and readiness for constant self-improvement;

5) ability to easily navigate in unusual situations;

6) adaptation to society and the ability to influence it;

7) ability to compromise and make a joint (collegial) decision;

8) tolerance;

9) perfect command of oral and written speech as a means of interpersonal interaction;

10) possession of modern information and communication technologies.

We consider it appropriate to note that "functional literacy" seems to be synonymous with another concept - soft skills, which are formed much earlier than "hard skills", which have a professional nature and are acquired in the process of professional training in vocational and higher education [12]. Such soft skills can be divided into three groups [13]:

1) skills related to personal qualities and attitudes (responsibility, discipline);

2) social skills that determine the success of adaptation in society, the ability to work in a team, emotional intelligence;

3) managerial skills, including critical thinking, willingness to lead, the ability to make decisions and be responsible for its consequences.

It is no coincidence that these soft skills are considered flexible. In foreign scientific and pedagogical literature, these skills are also called functional, and the result of their formation - functional literacy.

Undoubtedly, the reformation processes currently taking place in the New Ukrainian School (NUS) create the basis for the formation of all components of functional literacy. This is facilitated by the creation of a special educational environment and personal orientation of each student in it to form a personal semantic reflection of the scientific picture of the world through the constant expansion of concepts and ideas. 
The "three whales" of these transformations become educational environment of development (in NUS - it belongs to children), personification (harmonious combination of individualization and differentiation of learning) and motivation (based on reflection) of each subject of the educational process.

\section{Methods}

The methodological basis of our study is the competency approach, which is based on a set of hard and soft competencies, the mastery of which makes a person mobile, adapted to the needs of the changing labor market. In the program documents of UNESCO a kind of conglomeration of skills inherent in each individual, in which they are harmoniously combined. According to the International Board of Standards for Training, Achievement and Instruction, the concept of "competence" is presented as a set of knowledge, skills and attitudes that enable an individual to effectively carry out activities or perform certain functions aimed at to acquire certain standards in the profession or type of activity. A similar view of competence is presented in the Project Tuning - Project "Harmonization of Educational Structures in Europe" [14] as a dynamic combination of knowledge, understanding, skills, abilities and abilities, which can be attributed to the group of subject-specific or general. We follow the same approach, as it is the basis for the reform of primary school in Ukraine on the basis of the Concept of the New Ukrainian School.

In the course of research the complex of methods developed by us is applied. In particular, the following:

- surveys of parents to determine their attitude to the formation of functional literacy of primary school pupils,

- questionnaire of future primary school teachers to diagnose their readiness for the formation of functional literacy in pupils,

- ranking according to the degree of importance of the main components of functional literacy, which future teachers should form in pupils,

- testing to diagnose the readiness of future primary school teachers to form functional literacy in pupils by means of personality-oriented learning.

For the organization of research and experimental work we have developed an experimental program, the purpose of which is to diagnose the readiness of future primary school teachers to form functional literacy in pupils. The objectives of the experiment include:

1) development of the experimental program;

2) the choice of diagnostic methods to determine the readiness of future primary school teachers to form functional literacy in pupils;

3) implementation of quantitative and qualitative analysis of the obtained empirical data.
Diagnostics of readiness of future primary school teachers was carried out on the basis of Bohdan Khmelnytsky National University of Cherkasy: the study involved students of the final year in specialty 013 Primary education (educational degree "Bachelor" 64 - respondents).

The program of research and experimental work provides for three successive stages: organizational, basic and final. The first stage - organizational - is provided: choice of research topic, formulation of the conceptual apparatus (object, subject, goals and objectives of the study, a set of methods of psychological and pedagogical research); implementation of theoretical analysis of psychologicalpedagogical and scientific-methodical literature, legislative documents on the research problem; generalization of scientific achievements of famous scientists on issues that contribute to the solution of the chosen problem. In the second stage - basic - the following tasks are solved: choice of place for research and experimental work, respondents; establishing the possible duration of the experiment; choice of methods for diagnostics the readiness of future primary school teachers to form functional literacy in pupils. At the third stage - final - such work was carried out: the results of research and experimental work are described; quantitative and qualitative analysis of the obtained empirical data was performed.

When preparing for personality-oriented education of primary school pupils, future teachers must take into account the psychological patterns of formation of established behavioral skills and preferences, as well as stable personal formations. In this context, modern psychologists recommend future primary school teachers to distinguish between three levels of development and further implementation of socially necessary knowledge, norms, skills, values, which are broadcast by the social situation of development and the system of primary education, in particular:

- first level (“I know”) - awareness, learning, general motivation to change certain stereotypes of professional behavior of teachers,

- second level ("I can") - practical ability to apply the obtained information in new circumstances,

- third level ("I always do") - development of value preferences, sustainable modification of professional behavior in accordance with the acquired positive experience of independent implementation of values and behavioral strategies in real professional activity.

Based on the above, we propose to take into account the following criteria for the readiness of future primary school teachers to form functional literacy in pupils: gnostic (possession of information about the organization of personality-oriented learning); operational-activity (possession of methods, means and forms of organization of personality-oriented education of pupils); behavioral (positive experience of personality-oriented learning of primary school pupils, rejection of stereotypes, overcoming inertia).

A convincing argument for the formation of functional literacy in primary school pupils can be our survey of 
127 parents of pupils in the first class of primary school Cherkasy gymnasium No. 9 named after O. M. Lutsenko. The poll was conducted during a parent meeting at the beginning of the 2019-2020 school year. To our question "What do you think primary school should give your child?" the following answers were received from the parents: "primary school should inspire our child to be successful in today's world", "primary school must form in our child the will and character", "primary should teach our child to live among people", "primary school should teach our child to constantly improve throughout life". As we can see, the New Ukrainian School should take care of developing in each of its pupils' functional literacy as a priority human competence of the new millennium. To do this, every future primary school teacher in the process of professional training must take care of the development of new values, the most significant of which are the following:

- recognition of the priority of each pupils personality,

- creating comfortable conditions for self-expression of each pupil, able to respect not only themselves but also other participants in the educational process,

- recognition of the right of each pupil to self-realization,

- the realization that each student is special, has a talent for something,

- abandon grades as a tool to punish pupils,

- recognize that teachers and pupils are equal participants in the educational process,

- try to talk less to yourself and give pupils the opportunity to express themselves in class

- awareness that sometimes pupils may know more than the teacher,

- to provide each pupil with a free choice of a way of performance of the set task, to support its individual trajectory of development.

To diagnostics the readiness of future primary school teachers to form functional literacy in pupils, we have developed criteria and indicators. Criteria and corresponding indicators have been developed by us personally taking into account the ability of future primary school teachers to master and further implement socially necessary knowledge, norms, skills, values, which are transmitted by the social situation of development and the primary education system (table 1).

\section{Results}

A convincing argument in favor of the formation of functional literacy in pupils by means of personality-oriented learning can be our survey of 127 parents of first-graders of the primary school of Cherkasy gymnasium No. 9 named after O. M. Lutsenko. The survey was conducted during a parent meeting at the beginning of the 2019-2020 school year. To our question "What do you think elementary school should give your child?" the following answers were received from the parents: "primary school should teach our child to be successful in today's world", "primary school must form in our child the will and character", "primary should teach our child to live among people", "primary school should teach our child to constantly improve throughout life".

As we can see, the New Ukrainian School should take care of developing in each of its pupils' functional literacy as a priority human competence of the new millennium. To do this, every future primary school teacher must refocus in the process of professional training on the development of new values, the most significant of which are the following:

1) recognition of the priority of the personality of each people;

2) creating comfortable conditions for self-expression of each people, able to respect not only themselves but also other participants in the educational process;

3) recognition of the right of each people to selfrealization;

4) awareness that each people is special, has something in something;

5) abandon grades as a tool to punish pupils;

6) recognize that the teacher as well as the people is an equal participant in the educational process;

7) strive to speak less to yourself and give pupils the opportunity to express themselves in class;

8) awareness that sometimes pupils can know more than a teacher;

9) to provide each people with a free choice of a way of performance of the set task, to support its individual trajectory of development.

To diagnostics the readiness of future primary school teachers to form functional literacy in pupils, we conducted a survey of 64 students in specialty 013 Primary Education of Bohdan Khmelnytsky National University of Cherkasy. The poll was conducted during at the 20192020 school year. Respondents were asked to answer the following questions: "What features of pedagogical interaction you had to get acquainted with during pedagogical practice in primary school?"; "What made you happy or upset?"; "Which, in your opinion, is the reason for the unprofessional attitude to pedagogical interaction with pupils?"; "What methods or technologies do you use to provide person-centered learning?"; "What do you know about the functional literacy of primary school pupils?"; "Do you see a connection between the provision of personality-oriented learning and the formation of functional literacy in pupils?".

Elaboration of the received answers gave the following results. To the question "What features of pedagogical interaction you had to get acquainted with during pedagogical practice in primary school? What made you happy or upset?" respondents answered yes: "There is rudeness 
Table 1. Criteria and indicators of levels of readiness of future primary school teachers for the formation of functional literacy in pupils

Levels
gnostic (possession
of information about
the organization of
personality-oriented
learning)

operational-activity (possession of methods, means and forms of organization of personality-oriented education of pupils)

behavioral (positive experience of personalityoriented learning of primary school pupils, rejection of stereotypes, overcoming inertia)

High future teacher is well
versed in information
about the organization
of personality-oriented
learning, constantly improves its methodological level, shows complete independence, listens to the advice of teachers-mentors, methodists, deputies of the director

The future teacher perfectly masters the methods, means and forms of organization of personality-oriented education of pupils, seeks to diversify ways of pedagogical interaction, makes efforts to provide comfortable conditions for all participants in the educational process

The future teacher has his own positive experience of personality-oriented learning of pupils, abandons stereotypes, in pedagogical interaction seeks to overcome inertia, pays considerable attention to the moral values of pupils, their personal qualities and social skills
Sufficient

The future teacher has an idea of the organization of personality-oriented learning, according to the schedule of advanced training raises the methodical level, if necessary, seeks advice from the methodists, deputies of the director

The future teacher has methods, means and forms of organization of personality-oriented education of pupils, uses different ways of pedagogical interaction, focuses mainly on pupils

The future teacher has a positive experience of personality-oriented learning of pupils, seeks to move away from stereotypes, in pedagogical interaction overcomes inertia, pays attention to the education of moral values of pupils, their personal qualities and social skills

\begin{abstract}
Medium
The future teacher is aware of the organization of personality-oriented learning, but change the style of interaction with students in no hurry, cares about his methodological level, but does not always listen to the advice of teachers-mentors
\end{abstract}

The future teacher uses some methods, tools and forms of organization of personality-oriented learning of pupils, in pedagogical interaction prefers methods of control over the educational activities of pupils

The future teacher has experience of personalityoriented teaching of pupils, but is in no hurry to give up stereotypes, in pedagogical interaction is inert, takes over most of the powers, does not always pay attention to the moral values of pupils, their personal qualities and social skills and tactlessness between pupils and teachers, which sometimes turns into shouting" 50\% (32 respondents), "hostility" and "humiliation of the child" were stated $47 \%$ and $42 \%$ in accordance (30 and 27 respondents in accordance), "hypocrisy" and "deception" were observed $20 \%$ and $14 \%$ in accordance (13 and 9 respondents in accordance).

To the question "Which, in your opinion, is the reason for the unprofessional attitude to pedagogical interaction with pupils?" respondents answered yes: "not ready to meet modern society's demands" $70 \%$ (45 respondents), 65\% (42 respondents) consider their "practical training to provide person-centered learning satisfactory", $49 \%$ (31 respondents) "not satisfied with their methodological training", 61\% (39 respondents) feel "insufficient psychological readiness for change in the New Ukrainian school".

To the question "What methods or technologies do you use to provide person-centered learning?" most respondents (95\% or 61 persons) traditionally called "microphone", "group work", "openwork saw", as well as methods that became known thanks to innovations in the New
Ukrainian School - "Cubing (Bloom)", "Big Circle", "Solution Tree", "Working with Lego".

To the question "What do you know about the functional literacy of primary school pupils?" and "Do you see a connection between the provision of personalityoriented learning and the formation of functional literacy in pupils?" no response was received, indicating a lack of awareness of future primary school teachers in these issues.

The answers received during the survey confirm that future primary school teachers are not aware of the essence of functional literacy, are not aware of its structure, do not realize the importance of functional literacy in the education of a successful personality. However, future teachers have methods of organizing person-centered learning, able to apply the latest techniques common in European educational institutions in working with pupils of primary school.

The next task we propose to rank the main components of functional literacy, which should be formed in pupils, according to the degree of significance. To do this, we placed 10 components of functional literacy identified by 
Table 2. The results of ranking according to the degree of importance of the main components of functional literacy, which should be formed in pupils

\begin{tabular}{|c|c|c|}
\hline No. & Component of functional literacy & $\begin{array}{l}\text { Rating } \\
\text { place }\end{array}$ \\
\hline 1 & $\begin{array}{l}\text { orientation in the environment in accor- } \\
\text { dance with accepted values, expectations } \\
\text { and interests }\end{array}$ & 5 \\
\hline 2 & $\begin{array}{l}\text { the ability to make decisions indepen- } \\
\text { dently and take responsibility in a situ- } \\
\text { ation of choice }\end{array}$ & 6 \\
\hline 3 & $\begin{array}{l}\text { the ability to be responsible for decisions } \\
\text { made, as well as to be responsible for } \\
\text { their family members }\end{array}$ & 7 \\
\hline 4 & $\begin{array}{l}\text { formation of the ability to learn and } \\
\text { readiness for constant self-improvement }\end{array}$ & 3 \\
\hline 5 & $\begin{array}{l}\text { ability to easily navigate in unusual situ- } \\
\text { ations }\end{array}$ & 4 \\
\hline 6 & $\begin{array}{l}\text { adaptability to society and the ability to } \\
\text { influence it }\end{array}$ & 8 \\
\hline 7 & $\begin{array}{l}\text { the ability to compromise and make a } \\
\text { joint (collegial) decision }\end{array}$ & 9 \\
\hline 8 & tolerance & 10 \\
\hline 9 & $\begin{array}{l}\text { perfect command of oral and written } \\
\text { speech as a means of interpersonal inter- } \\
\text { action }\end{array}$ & 2 \\
\hline 10 & $\begin{array}{l}\text { possession of modern information and } \\
\text { communication technologies }\end{array}$ & 1 \\
\hline
\end{tabular}

us in one column, and in the second we proposed to put a number that corresponds to the degree of significance of each component in the structure of functional literacy. The answers were distributed as follows (table 2).

From the data obtained in the table we can conclude that future primary school teachers stereotypically prioritize in person-centered learning and continue to give preference to digital skills, literate oral and written speech, and the ability to learn. However, they do not attach much importance to the important qualities of functionally literate pupils, which indicates a lack of understanding of this competence.

Also for diagnostics of readiness of future primary school teacher to formation of functional literacy at pupils we carried out testing of students of a final course specialty in 013 Primary Education of Bohdan Khmelnytsky National University of Cherkasy:

Dear students! Please agree or disagree the following sentences by choosing one of the two suggested answers "yes" or "no":

1. Orientation in the environment in accordance with accepted values, expectations and interests is a sign of functional literacy of the individual.

2. The ability to make independent decisions and take responsibility in the situation of choice is important for the functional literacy of the individual.
3. Functionally literate person is able to be responsible for the decisions made, as well as be responsible for their family members.

4. The formation of the ability to learn and readiness for continuous self-improvement is a characteristic feature of a functionally literate personality.

5. Functionally literate person is able to easily navigate in unusual situations.

6. One of the signs of functional literacy of the individual is adaptability to society and the ability to influence it.

7. A functionally literate person is characterized by the ability to compromise and make a collegial decision.

8. A functionally literate person is necessarily tolerant.

9. Perfect command of oral and written speech as a means of interpersonal interaction is inherent in a functionally literate personality.

10. An important quality of a functionally literate person is the possession of modern information and communication technologies.

For each answer "yes" put 1 point, and for each answer "no" - 0 points. Add the points to get the amount. Interpretation of the obtained result: students, who received from 8 to 10 points, have a high level of functional literacy. Students, who received from 5 to 7 points, have a sufficient level of functional literacy. Students, who received from 1 to 4 points, have a medium level of functional literacy.

According to the results, $10 \%$ (6 respondents) future teachers received from 8 to 10 points, which indicates a high level of their readiness to form functional literacy of primary school pupils. They are well versed in information about the organization of personality-oriented learning, care about improving their methodological level, are able to show complete independence, listen to the advice of teachers, mentors, methodologists. They are well versed in the methods, tools and forms of organization of personality-oriented learning of primary school children, seek to diversify ways of pedagogical interaction, make efforts to provide comfortable conditions for all participants in the educational process. In addition, they have their own positive experience of personality-oriented learning of primary school children, ready to abandon stereotypes, in pedagogical interaction seek to overcome inertia, considerable attention is paid to the moral values of students, their personal qualities and social skills.

$7 \%$ (4 respondents) future teachers received from 5 to 7 points, which indicates a sufficient level of their readiness to form functional literacy of primary school pupils. They have an idea of the organization of personalityoriented learning, ready to increase their methodological level, if necessary, seek advice from a methodologist, mentor. They have the methods, means and forms of organizing personality-oriented learning of primary school children, can use different methods of pedagogical interaction, but focus mainly on pupils' achievement. They also 
have a positive experience of personality-oriented learning of pupils, seek to move away from stereotypes, in pedagogical interaction are ready to overcome inertia, pay attention to the education of moral values of pupils, their personal qualities and social skills.

The remaining future teachers $-83 \%$ (54 respondents) received from 1 to 4 points, which indicates the medium level of their readiness to form functional literacy of primary school pupils. They are familiar with the organization of personality-oriented learning, but do not rush to change the style of interaction with pupils, care about their methodological level, but do not always listen to the advice of teachers-mentors. They can use certain methods, tools and forms of organization of personality-oriented learning of primary school pupils', however, in pedagogical interaction they prefer methods of control over pupils educational activities. They also have experience in personalityoriented learning of pupils, although they are in no hurry to abandon stereotypes, so they are inert in pedagogical interaction, take on most of the authority, do not always pay attention to the moral values of pupils, their personal qualities and social skills.

Research and experimental work on the diagnosis of the readiness of the future primary school teacher to form the functional literacy of pupils by means of personalityoriented learning is organized in accordance with the previously developed program, which provides: the purpose and objectives of the experiment; place and time of the experiment, its scope; characteristics of the participants of the experiment; description of materials to be used in the experiment; step-by-step course of the experiment; methods of monitoring the progress of the experiment; description of the method of processing the results of the experiment; description of the method of interpretation of the experimental results. To establish the levels of readiness of future primary school teachers to form functional literacy of pupils by means of personality-oriented learning, we identified gnostic, operational and behavioral criteria and corresponding indicators, which allowed respondents to find high, sufficient and medium levels of readiness.

According to the results of questionnaires and testing, $10 \%$ (6 respondents) future teachers have a high level of readiness for the formation of functional literacy of primary school pupils, $7 \%$ (4 respondents) - sufficient level i $83 \%$ (54 respondents) - medium level. The ranking of the components of functional competence by future primary school teachers confirms that they stereotypically prioritize personality-oriented learning and continue to give priority to digital skills, literate oral and written speech, and the ability to learn. However, they do not attach much importance to the important qualities of a functionally literate child, which indicates their lack of understanding of this competence.

The obtained results are taken into account when updating the curriculum for bachelors majoring in 013 Primary Education. For this purpose, a special course "New Ukrainian school: components, methods, competencies" was additionally introduced, the content of which was expanded with practically oriented material, acquaintance with which will allow to effectively form the following components of functional literacy in pupils: orientation in the environment in accordance with accepted values, expectations and interests; formation of ability to learn and readiness for constant self-improvement; perfect command of oral and written speech as a means of interpersonal interaction; possession of modern information and communication technologies.

The introduction of the elective course "Tolerance and non-discrimination in the educational environment" will help future primary school teachers to develop tolerance, as well as the ability to compromise and make joint (collegial) decisions. Studying the elective course "Gender Pedagogy" involves developing in them the ability to be responsible for the decisions made, as well as to be responsible for their family members. Mastering the elective course "Pedagogy of Equal Opportunities" will form the ability of future teachers to make decisions independently and take responsibility in the situation of choice. We also updated the content of syllabus from the disciplines "Theory and methods of education in primary school", "Didactics and school science", "Introduction to the specialty "Primary education". This will allow future primary school teachers to develop such components of functional literacy as the ability to easily navigate in non-standard situations, as well as adaptability to society and the ability to influence it.

\section{Conclusions}

The study confirms the achievement of this goal - the attitude of future primary school teachers to the need for the formation of functional literacy in pupils. For the first time we have established the dependence of the formation of functional literacy of pupils on the use of personalityoriented learning - learning based on the recognition of individuality, identity, self-worth of each child, its development as an individual endowed with unique subjective experience. It was found that compared to the previous century, when the first attempts were made to implement humanistic learning, pedagogy of cooperation, at the beginning of the new millennium, the implementation of the content of personality-oriented learning is determined by the project method, interactive interaction method, portfolio method, research method and other methods.

According to the goal, a number of tasks have been solved. Thus, the essence of the concept of "functional literacy" is specified as the ability of an individual to apply all lifelong knowledge, skills and abilities to solve the widest possible range of life tasks in various fields of activity, communication and social relations.

It is analyzed that the structure of functional literacy includes 10 components (orientation in the environment in accordance with accepted values, expectations and interests; ability to make independent decisions and take responsibility in a situation of choice; the ability to be responsible for decisions made, as well as to be responsible for family members; formation of ability to learn and readiness for constant self-improvement; ability to easily navigate in unusual situations; adaptability to society and the ability to influence it; ability to compromise and make 
a joint (collegial) decision; tolerance; perfect command of oral and written speech as a means of interpersonal interaction; possession of modern information and communication technologies). In terms of content, these components are close to soft skills, and their formation in early school age will affect the successful socialization of children to environmental conditions.

In the course of the research we determined the attitude of parents of pupils to the need to form functional literacy. It was found that parents strive to see their children successful in the modern world, to have formed the will and character, to be able to adequately socialize, to constantly improve throughout life.

The diagnosis of the formation of functional literacy in future primary school teachers confirms, that only $10 \%$ of them (6 respondents) have a high level of readiness for the formation of functional literacy of pupils, $7 \%$ (4 respondents) - a sufficient level and $83 \%$ (54 respondents) - an average level. The ranking of the components of functional competence by future primary school teachers shows that they stereotypically prioritize in personalityoriented learning and continue to give preference to digital skills, literate oral and written speech, the ability to learn. However, future teachers do not attach much importance to the important qualities of a functionally literate child, which indicates that they lack an understanding of this competence.

The research conducted here does not exhaust the solution of the chosen problem. Forms and methods of training of future primary school teachers for the formation of functional literacy in pupils need further research. The most optimal conditions for training of future teachers for the formation of functional literacy in pupils need to be developed.

\section{References}

[1] O. Kovshar, M. Baditsa, K. Suiatynova, International Journal of Engineering and Advanced Technology 9, 4556 (2019)

[2] Soft skills: universal skills of the European level, https://tinyurl.com/weehrjb8

[3] L. Sultanova, V. Hordiienko, G. Romanova, K. Tsytsiura, Journal of Physics: Conference Series 1840, 012038 (2021)

[4] I.P. Varava, A.P. Bohinska, T.A. Vakaliuk, I.S. Mintii, Journal of Physics: Conference Series (2021, in press)

[5] UNESCO, SDG 4 Ensure inclusive and equitable quality education and promote lifelong learning opportunities for all, http://tcg.uis.unesco. org/wp-content/uploads/sites/4/2020/08/ Metadata-4.6.1.pdf

[6] Literacy initiative for empowerment, life: vision and strategy paper 2005-2015 (2006)

[7] A. Shtets, Primary School: Plus Before and After pp. 69-72 (2007)

[8] K. Kyselova, PISA results in Ukraine: what are our strengths (2019), https://tinyurl.com/ $4 \mathrm{sc} 67 \mathrm{wdw}$

[9] M. Kondracka-Szala, J. Malinowska, The New Educational Review 58, 239 (2019)

[10] S. Shami, N. Nastiezaie, The New Educational Review 58, 184 (2019)

[11] R. Treesuwan, T. Tanitteerapan, The New Educational Review 45, 151 (2016)

[12] A. Abdula, H. Baluta, N. Kozachenko, D. Kassim, CEUR Workshop Proceedings 2643, 306 (2020)

[13] P.E. Chukwuneme, I. Mbukanma, J.C. Ebere, The New Educational Review 47, 81 (2017)

[14] Tuning Educational Structures in Europe, http:// www . unideusto.org/tuningeu/ 